\title{
АМИНОКИСЛОТНЫЙ, ЖИРНОКИСЛОТНЫЙ И ПОЛИСАХАРИДНЫЙ СОСТАВ ТРАВЫ ТИМЬЯНА ПАЛЛАСА (THYMUS PALLASIANUS L.)
}

\author{
() В.Н. Бубенчикова ${ }^{*}$ Ю.А. Старчак \\ Курский государственный медицинский университет, ул. К. Маркса, 3, Курск, \\ 305041, (Россия), e-mail: fg.ksmu@mail.ru
}

\begin{abstract}
Приведены данные по изучению аминокислотного, жирнокислотного и углеводного состава травы тимьяна Палласа. Аминокислотный состав представлен 16 веществами, среди которых основными являются лейцин, аланин и цистин. Высокая концентрация среди жирных кислот отмечена для пальмитиновой $(769,1$ мг/кг), олеиновой $(132,0$ мг/кг), линолевой $(282,1$ мг/кг) и линоленовой $(519,5$ мг/кг) кислоты. Изучение качественного и количественного моносахаридного состава показало, что преобладающими моносахаридами в водорастворимом полисахаридном комплексе (ВРПС) являются арабиноза (8,62\%), ксилоза (12,10\%); основу пектиновых веществ (ПВ) составляет галактуроновая кислота $(91,30 \%)$, основу гемицеллюлозы А (Гц А) и гемицеллюлозы Б (Гц Б) - ксилоза (8,30 и 7,90\% соответственно).

Ключевые слова: тимьян Палласа, аминокислоты, жирные кислоты, водорастворимые полисахарида, пектиновые вещества, гемицеллюлоза А, Б.
\end{abstract}

\section{Введение}

На территории Средней полосы европейской части России произрастает 8-9 видов растений рода тимьян (Thymus L.), сырье которых зачастую заготавливают как равноценное под названием «Трава чабреца» [1]. Растения рода тимьян содержат различные классы биологически активных веществ, и все виды отличаются друг от друга по качественному и количественному составу биологически активных веществ, содержащихся в них [1]. В связи с этим нами проведено изучение аминокислотного, жирнокислотного и полисахаридного состава травы тимьяна Палласа.

\section{Экспериментальная часть}

Объектом исследования служила трава тимьяна Палласа, заготовленная в Воронежской области (окрестности г. Лиски) в 2012 г. в фазу цветения растений.

Состав аминокислот и их содержание определяли с помощью нингидриновой реакции и хроматографии в тонком слое сорбента, а также с помощью аминокислотного анализатора АAА339M (Чехия) [2-4].

Для определения общего содержания аминокислот траву тимьяна Палласа исчерпывающе экстрагировали и гидролизовали горячей водой очищенной в присутствии кислоты хлористоводородной концентрированной. Полученный гидролизат фильтровали, упаривали в вакууме до объема $0,5-1,0$ мл, доводили $\mathrm{pH}$ полученной пробы до 2,2. Для определения общего содержания аминокислот к 1,0 мл пробы прибавляли 1,0 мл натриево-цитратного буфера (pH 2,2) и проводили анализ на аминокислотном анализаторе. Анализ аминокислот проводили в стандартных условиях, обычно используемых для разделения белковых гидролизатов [3]. Для количественной оценки определяли (автоматически) площади пиков идентифицированных аминокислот. Количество каждой идентифицированной аминокислоты определяли в наномолях и нанограммах в аликвоте,

Бубенчикова Валентина Николаевна - заведующая кафедрой фармакогнозии и ботаники, доктор фармацевтических наук, профессор,

e-mail: fg.ksmu@mail.ru

Старчак Юлия Анатольевна - ассистент кафедры общей и фармацевтической химии, кандидат фармацевтических наук, e-mail: yuliya-starchak@yandex.ru непосредственно использованной для анализа. Затем было рассчитано общее содержание аминокислот в мг/100 мл.

Для определения связанных аминокислот навеску сухого сырья предварительно экстрагировали 80\%-ным этиловым спиртом, а затем пробу заливали

\footnotetext{
* Автор, с которым следует вести переписку.
} 
очищенной водой и концентрированной хлористоводородной кислотой, гидролизовали и далее определяли содержание аминокислот по описанной выше методике. Концентрацию свободных аминокислот рассчитывали как разность между концентрацией общего содержания аминокислот и концентрацией связанных аминокислот.

Исследование липидных веществ (жирных кислот) проводили методом газо-жидкостной хроматографии [5]. Для анализа 50,0 мг измельченного воздушно-сухого сырья тимьяна Палласа помещали в виалу «Agilent» на 2,0 мл, прибавляли 50,0 мкг тридекана в гексане (внутренний стандарт) и 1,0 мл метилирующего агента (14\% $\mathrm{BCl}_{3}$ в спирте метиловом, Supelco 3-3033). Смесь выдерживали в герметично закрытой виале 8 ч при температуре $65^{\circ} \mathrm{C}$. За это время из растительного материала полностью извлекается жирное масло, происходит его гидролиз на составляющие жирные кислоты с одновременным их метилированием. Далее реакционную смесь сливали с растительного сырья и разбавляли 1,0 мл воды очищенной. Извлечение метиловых эфиров жирных кислот проводили хлористым метиленом, а затем их хроматографировали на газо-жидкостном хроматографе Agilent Technologies 6890 с масс-спектрометрическим детектором 5973N. Условия анализа: хроматографическая колонка - капиллярная INNOWAX, длиной 30 м, внутренний диаметр 0,25 мм; газ-носитель - гелий, скорость газа-носителя - 1,2 мл/мин, объем пробы - 2 мкл; скорость ввода пробы - 1,2 мл/мин в течение 0,2 мин; температура термостата программируется от 50 до $250{ }^{\circ} \mathrm{C}$ со скоростью $4{ }^{\circ} \mathrm{C} /$ мин; температура нагревателя ввода пробы $250{ }^{\circ} \mathrm{C}$. Идентификацию жирных кислот осуществляли путем сравнения с заведомыми образцами метиловых эфиров, а также используя библиотеку масс-спектров NISTO5 и WILLEY 2007 с общим количеством спектров более 470000 в сочетании с программами для идентификации AMDIS и NIST. Концентрации индивидуальных жирных кислот рассчитывали методом внутреннего стандарта $[4,5]$.

Для изучения полисахаридного состава воздушно-сухое измельченное сырье предварительно обрабатывали 70\%-ным спиртом этиловым для удаления полифенольных соединений, затем водой очищенной экстрагировали водорастворимые полисахариды в соотношении $1: 20$ к массе сырья при нагревании до $95{ }^{\circ} \mathrm{C}$ в течение 2 ч при постоянном перемешивании. Повторное извлечение полисахаридов проводили дважды водой очищенной в соотношении 1:10. Растительный материал отделяли центрифугированием и объединенные извлечения упаривали до 1/5 первоначального объема. Полисахариды осаждали тройным объемом 96\%-ного этилового спирта при комнатной температуре. Выпавший плотный осадок водорастворимых полисахаридов отделяли, промывали 70\%-ным этиловым спиртом, ацетоном. Полученный водорастворимый полисахаридный комплекс лиофильно высушивали [6].

Из шрота, оставшегося после получения водорастворимых полисахаридов, выделяли пектиновые вещества экстракцией смесью $0,5 \%$ растворов кислоты щавелевой и аммония оксалата $(1: 1)$ в соотношении 1:20 при 80-85 ${ }^{\circ} \mathrm{C}$ в течение 2 ч. Повторное извлечение проводили дважды в соотношении 1:10. Объединенное извлечение концентрировали и осаждали пятикратным объемом 96\%-ного спирта этилового. Полученный осадок отфильтровывали, промывали спиртом этиловым, высушивали и взвешивали [6].

Шрот, оставшийся после выделения пектиновых веществ, заливали пятикратным объемом 10\%-ного водного раствора натрия гидроксида и оставляли при комнатной температуре на 12 ч. Затем отфильтровывали, к полученному фильтрату прибавляли два объема кислоты уксусной. Образовавшийся осадок отфильтровывали через фильтр. На фильтре получился осадок гемицеллюлозы А в виде зеленоватокоричневой массы. К фильтрату добавляли двукратный объем 96\%-ного спирта этилового для осаждения гемицеллюлозы Б. Полученный осадок отфильтровывали через фильтр, промывали 96\%-ным этиловым спиртом, высушивали [6].

Исследование моносахаридного состава полисахаридных комплексов проводили методом хроматографии на бумаге после гидролиза 2 М кислотой серной при температуре $100-150{ }^{\circ} \mathrm{C}$ в течение 6 ч (для ВРПС), 24 ч (для пектиновых веществ) и 48 ч (для Гц А и Гц Б). Разделение и идентификацию нейтральных моносахаридов проводили методом нисходящей хромотографии на бумаге в системе растворителей $\mu$-бутанол - пиридин - вода $(6: 4: 3)$ на параллельно со стандартными образцами сахаров. Кислые моносахара разделяли в системе: этилацетат - кислота муравьиная - вода - кислота уксусная (18: $1: 4: 3)$. Проявитель - анилин фталат, температура проявления - 100 $\mathrm{C}$, длительность проявления - 10-15 мин [6].

\section{Результаты и обсуждение}

В результате изучения аминокислотного состава травы тимьяна Палласа установлено, что он представлен 16 соединениями (табл. 1). Содержание свободных аминокислот составляет 0,95 мг/100 мг, среди них наибольшее содержание отмечено у цистина (0,21 мг/100 мг) и аланина $(0,13$ мг/100 мг). Содержание 
связанных аминокислот составляет 8,56 мг/100 мг, среди которых преобладают аланин $(1,12$ мг/100 мг), цистин (1,12 мг/100 мг) и лейцин (1,11 мг/100 мг).

Результаты изучения жирнокислотного состава показали наличие 15 жирных кислот. Среди них в большом количестве встречается насыщенная жирная кислота: пальмитиновая (769,1 мг/кг), а также линолевая (282,1 мг/кг) и линоленовая кислоты (519,5 мг/кг) (табл. 2).

При изучении полисахаридного состава были выделены полисахариды по фракциям (табл. 3). Выход водорастворимого полисахаридного комплекса составил 4,63\%. Он представляет собой аморфное вещество светло-коричневого света, без запаха, хорошо растворим в воде, дает положительные реакции осаждения со спиртом этиловым, ацетоном, реакцию Фелинга после кислотного гидролиза.

Выход пектиновых веществ составил 14,01\% от массы воздушно-сухого сырья. Пектиновый комплекс представляет собой порошок светло-кремового цвета, без запаха, хорошо растворим в воде с образованием вязкого раствора (рН 1\%-ного водного раствора - 3-4). Водный раствор пектиновых веществ осаждается $1 \%$-ным раствором алюминия сульфата с образованием пектатов. Выход гемицеллюлозы А составил 0,56\%, а гемицеллюлозы Б - 7,15\% от массы воздушно-сухого сырья.

Методом хроматографии на бумаге параллельно с достоверными образцами сахаров в исследуемом ВРПС идентифицировали глюкозу, галактозу, арабинозу, рамнозу, ксилозу, глюкуроновую и галактуроновые кислоты, с преобладанием ксилозы и арабинозы. В выделенном пектиновом комплексе преобладающей является галактуроновая кислота, кроме того, в нем обнаружены и нейтральные моносахариды: галактоза, арабиноза, глюкоза и рамноза.

В гидролизатах Гц А и Гц Б идентифицированы галактоза, арабиноза, глюкоза, ксилоза, рамноза, преобладающей среди них является ксилоза, что указывает на наличие полисахаридов типа ксиланов. Декситометрически в гидролизатах выделенных полисахаридных комплексов было установлено количественное содержание моносахаров (табл. 3).

Таблица 1. Содержание и состав свободных и связанных аминокислот травы тимьяна Палласа, (мг/100 мг воздушно сухого сырья)

\begin{tabular}{l|c|c}
\hline \multicolumn{1}{c|}{ Наименование } & $\begin{array}{c}\text { Содержание } \\
\text { свободных } \\
\text { аминокислот }\end{array}$ & $\begin{array}{c}\text { Содержание } \\
\text { связанных } \\
\text { аминокислот }\end{array}$ \\
\hline Аспарагиновая кислота & 0,03 & 0,32 \\
Треонин & 0,02 & 0,21 \\
Серин & 0,03 & 0,15 \\
Цистин & 0,21 & 1,12 \\
Глицин & 0,04 & 0,47 \\
Аланин & 0,13 & 1,12 \\
Валин & 0,04 & 0,28 \\
Метионин & 0,03 & 0,24 \\
Изолейцин & 0.06 & 0,71 \\
Лейцин & 0,08 & 1,11 \\
Тирозин & 0,03 & 0,37 \\
Фенилаланин & 0,03 & 0,42 \\
Гистидин & 0,04 & 0,55 \\
Лизин & 0,09 & 0,53 \\
Аргинин & 0,09 & 0,96 \\
\hline Сумма аминокислот & 0,95 & 8,56 \\
\hline
\end{tabular}

Таблица 2. Жирнокислотный состав липидов травы тимьяна Паласа

\begin{tabular}{l|c}
\hline \multicolumn{1}{c|}{ Наименование } & $\begin{array}{c}\text { содержание жирных } \\
\text { кислот, мг/кг }\end{array}$ \\
\hline Миристиновая & 39,1 \\
Пандекановая & 14,9 \\
Пальмитиновая & 769,1 \\
Пальмитолеиновая & 54,2 \\
Гептадекановая & 16,5 \\
Стеариновая & 5,8 \\
Олеиновая & 132,0 \\
11-октадеценовая & 19,1 \\
Линолевая & 282,1 \\
Линоленовая & 519,5 \\
Арахиновая & 51,7 \\
Хенейкозеновая & 6,2 \\
Бегеновая & 62,4 \\
Гексадекадионовая & 46,5 \\
Тетракозановая & 20,3 \\
\hline
\end{tabular}

Таблица 3. Содержание моносахаридов в полисахаридных комплексах травы тимьяна Палласа, \%

\begin{tabular}{|c|c|c|c|c|}
\hline \multirow{2}{*}{ Наименование моносахаридов } & \multicolumn{4}{|c|}{ Полисахаридные комплексы } \\
\hline & ВРПС & ПВ & Гц А & Гц Б \\
\hline Арабиноза & $8,62 \pm 1,28$ & $2,10 \pm 3,33$ & $1,40 \pm 5,00$ & $1,70 \pm 4,71$ \\
\hline Галактоза & $4,09 \pm 2,45$ & $1,60 \pm 5,00$ & $2,70 \pm 4,07$ & $2,30 \pm 3,91$ \\
\hline Глюкоза & $5,20 \pm 2,12$ & $1,40 \pm 5,00$ & $2,30 \pm 4,78$ & $2,90 \pm 3,10$ \\
\hline Ксилоза & $12,10 \pm 0,91$ & - & $8,30 \pm 1,08$ & $7,90 \pm 1,14$ \\
\hline Рамноза & $0,10 \pm 3,93$ & $0,10 \pm 3,93$ & $0,10 \pm 3,93$ & $0,10 \pm 3,93$ \\
\hline Галактуроновая кислота & $2,40 \pm 3,75$ & $91,31 \pm 3,87$ & - & - \\
\hline Глюкуроновая кислота & $1,60 \pm 4,38$ & - & - & - \\
\hline
\end{tabular}




\section{Выводы}

1. В траве тимьяна Палласа обнаружено 16 аминокислот. Содержание свободных аминокислот составляет 0,95 мг/100 мг, связанных 8,56 мг/100 мг. Основными азотосодержащими соединениями являются лейцин, аланин и цистин.

2. Жирнокислотный состав представлен 15 соединениями, из них высокая концентрация отмечена для пальмитиновой (769,1 мг/кг), олеиновой $(132,0$ мг/кг), линолевой $(282,1$ мг/кг) и линоленовой (519,5 мг/кг) кислот.

3. Выделенные полисахариды по фракциям: водорастворимый полисахаридный комплекс, пектиновые вещества, гемицеллюлоза А и гемицеллюлоза Б. Изучен их качественный и количественный моносахаридный состав. Преобладающими моносахаридами в ВРПС являются арабиноза $(8,62 \%)$ и ксилоза $(12,10 \%)$; основу пектиновых веществ составляет галактуроновая кислота $(91,31 \%)$, основу Гц А и Гц Б ксилоза $(8,30$ и 7,90\% соответственно).

\section{Список литературы}

1. Банаева Ю.А., Покровский Л.М., Ткачёв А.В. Исследование химического состава эфирного масла представителей рода Thymus L., произрастающих на Алтае // Химия растительного сырья. 1999. № 3. С. 41-48.

2. Бубенчикова В.Н., Сухомлинов Ю.А., Гончаров Н.Ф. Аминокислотный состав некоторых представителей растений семейства розоцветных // Человек и его здоровье. 2009. № 3. С. 134-137.

3. Бубенчиков Р.А. Аминокислотный и минеральный состав травы фиалки удивительной // Вестник Воронежского государственного университета. Серия Химия. Биология. Фармация. 2006. № 1. С. 186-188.

4. Шуляковская Т.А., Ветчинникова, Л.В. Ильинова М.К., Канючкова Г.К., Репин А.В., Веселкова Л.Л. Аминокислотный, жирнокислотный и углеводный состав сока некоторых видов рода Betula // Растительные pecypсы. 2006. Т. 42, вып. 2. С. 69-77.

5. Carrapiso A. I., Carcia C. Development in lipid analysis: some new extraction techniques and in situ transesterification // Lipids. 2000. № 35. Pp. 1167-1177.

6. Бубенчикова В.Н., Старчак Ю.А. Фенольные соединения и полисахариды подмаренника цепкого (Galium aparine L.) // Человек и его здоровье. 2008. № 3. С. 117-121.

Поступило в редакиию 9 октября 2013 г. После переработки 11 ноября 2013 г.

Bubenchikova V.N. , Starchak Yu.A. THE AMINO ACID, FATTY ACID AND POLYSACCHARIDES COMPOSITION OF THE THYMUS PALLASIANUS L. HERB

Kursk State Medical University, K.Marks str., 3, Kursk, 305041, (Russia),e-mail:fg.ksmu@mail.ru

The article presents the results of analysis of amino acid, fatty acid and carbohydrate composition of the Thymus pallasianus L. herb. The amino acid composition is represented by 16 substances, among which are leucine, alanine and cystine. A high concentration of fatty acids marked for palmitic $(769,1 \mathrm{mg} / \mathrm{kg})$, oleic $(132,0 \mathrm{mg} / \mathrm{kg})$, linoleic $(282,1 \mathrm{mg} / \mathrm{kg}) \mathrm{and}$ linolenic $(519,5 \mathrm{mg} / \mathrm{kg})$ acid. The study of the qualitative and quantitative monosaccharide composition showed that the predominant monosaccharides in water-soluble polysaccharide complexes are arabinose $(8,62 \%)$, xylose $(12,10 \%)$; the basis of pectins is galacturonic acid (91,30\%); the basis of hemicellulose A and B - xylose (8,30 and 7,90\% respectively).

Keywords: Thymus pallasianus L., amino acids, fatty acids, water-soluble polysaccharides, pectins, hemicellulose A and B.

\section{References}

1. Banaeva Ju.A., Pokrovskij L.M., Tkachjov A.V. Himija rastitel'nogo syr'ja, 1999, no. 3, pp. 41-48.

2. Bubenchikova V.N., Suhomlinov Ju.A., Goncharov N.F. Chelovek i ego zdorov'e, 2009, no. 3, pp. 134-137.

3. Bubenchikov R.A. Vestnik Voronezhckogo Gosudarstvennogo Universiteta, 2006, no. 1, pp. 186-188.

4. Shuljakovskaja T.A., Vetchinnikova, L.V. Il'inova M.K., Kanjuchkova G.K., Repin A.V., Veselkova L.L. Rastitel'nye resursy, 2006, vol. 42, issue 2, pp. 69-77.

5. Carrapiso A. I., Carcia C. Lipids, 2000, no. 35, pp. 1167-1177.

6. Bubenchikova V.N., Starchak Ju.A. Chelovek i ego zdorov'e, 2008, no. 3, pp. 117-121.

\footnotetext{
* Corresponding author.
} 